\title{
Science Blogs as Critique- Building Public Identities in the Field of Translational Research
}

\author{
Barbara Hendriks \\ Humboldt-Universität zu Berlin, Germany/barbara.hendriks@hu-berlin.de
}

\section{Martin Reinhart}

Humboldt-Universität zu Berlin, Germany

\begin{abstract}
Clinician scientists are pivotal figures in translational research. Although the discourse on translational research is favorable to clinician scientists, their role within it and their view of themselves has received little attention. In this exploratory study, we analyze the view of clinician scientists on translational research by drawing on surveillance studies and the pragmatic sociology of critique and examining the potential for critique of science blogs. From analyzing science blogs and the blogging selves they represent, we find a fundamental dilemma of being torn between the two worlds of clinic and research. Although translational research seeks to support clinician scientists, it intensifies this conflict even further. The arguments of clinician scientist-bloggers are emotionally charged with feelings of contradiction, unpredictability, and skepticism. These feelings undergird a critical agenda that shows indignation as the result of being a pivotal figure in the discourse on translational research.
\end{abstract}

Keywords: translational research, clinician scientists, science blogs, sociology of critique, sociology of professions, science communication, public identity

\section{Introduction}

Calls for fundamental changes in the organization of research practices in the biomedical field are clearly discernible, and the calls to enact these changes are notably directed at clinician scientists. Claims of serious deficits in the innovation process and of inefficiencies in research practices ('waste') have been brought forward and linked to roadblocks in the translation from research findings into effective clinical practice and the other way round. Commonly referred to as a 'transla- tion gap', a more general shift in the discourse is apparent that emphasizes the term 'translational research' (Contopoulos-loannidis et al., 2003). The starting point of translational research is the problematization of current practices in the health care innovation system by especially paying attention to transition stages between basic research, clinical research and public health. In that regard, multiple stakeholders refer to translational research in order to address questions regarding the 
reorganization and improvement of biomedical research practices. These questions range from methodological, e.g. regarding reproducibility or randomization of experiments, to organizational, e.g. regarding interdisciplinarity and interorganizational communication, to regulatory issues, e.g. regarding guidelines based on meta-reviews or additional funding for regulatory staff. For these questions one group of actors promises to hold the necessary interactional expertise and to carry the translational shift: clinician scientists. Fulfilling two roles at once, the clinician scientist is perceived as the essential conduit between biomedical research and clinical practice (Lemoine, 2008).

The expectation of fulfilling two roles in one is an excessive demand on everyday practice and results in "situations of crisis" (Boltanski and Thévenot, 1999) for individual clinician scientists. Solutions to the crises are left to the individuals, due to the fact that clinician scientists do not represent an independent profession with institutional platforms, e.g. the Office of the Profession in New York (US) (http://www.op.nysed. gov/), (educational) departments and systems, or rules of professional conduct for justifying needs and concerns. However, one platform where such professional issues can be discussed and observed are science blogs, of which there are a sizeable number authored by clinician scientists. Multiple studies have called attention to the fact that blogging contributes to the empowerment (Farrell and Sides, 2010; Farrell and Drezner, 2008) and development of professions (Ezzamel, 2013; Bodell et al., 2009).

Our interest lies in how clinician scientists participate in the discourse on translational research and how their role as clinician scientists is performed by speaking out with respect to their individual crises as a form of critique. An active community of clinician scientists publicizes their daily working practices, challenges and tasks in the context of translational research on science blogs. In the tradition of science communication research (Bucchi, 1998; Shanahan, 2011; Bonetta, 2007; Kouper, 2010), we focus on the meaning of new media forms for scientific practice. We provide an exploratory analysis of these blogs with respect to three questions: How do clinician scientists describe and problematize their position? How do they contribute to the discourse on translational research? How do science blogs provide a venue for critique in the public context of translational research? In answering these questions, we contribute to the ongoing debate on the role of new forms of science communication, such as science blogs, in building public scientific identities. Following a neo-pragmatist perspective (Boltanski and Thévenot, 1999, 2006), we performed a three-tiered analysis disclosing self-images of clinician scientists: We find that (1) clinician scientists see themselves in a dilemma between the two worlds of clinic and research, leaving them too little time to be simultaneously successful as researchers and as clinicians. (2) Translational research as a professional framework remains vague and devoid of guidance for translational practice, thus, exacerbating this conflict. (3) Being a pivotal figure in the discourse on translational research, blogging clinician scientists present themselves as affected by contradiction, unpredictability, and skepticism. As a result, their professional agenda is articulated in a mode of critique based on indignation.

\section{The crisis in biomedical research and the emergence of translational research}

The discourse on translational research has its roots in the USA, which is well reflected in the development of the journal landscape on translational research in biomedicine (Blümel et al., 2015). As such, the recent history of translational research is strongly tied to the North American context, from where it has spread globally over the last two decades. The wide spread has, partly, been made possible by the fact that the term translational research remains unspecific and malleable (Butler, 2008). Translational research functions as an empty signifier in most situations, for instance, as it does not contain any specific practical advice for 'doing translation'. Translational research as a research framework has thus developed an overall global character. Its compatibility allows various stakeholders from different nations, institutions, and research fields to take part in the discourse 
and to voice their agenda through translational issues (Krüger et al., 2018).

A brief history of the emergence of translational research within the last four decades has to take note first of increased efforts and investments into research and development $(R \& D)$ in the field of biomedical research while simultaneously the output of novel therapies has been declining (Wehling, 2008; Center Watch, 2016). Investments in $R \& D$ in biomedicine rose from $\$ 13,6$ billion to over \$27 billion from 1993 to 2003 and led to higher expectations for innovation, which has largely resulted in disappointment (Kraft, 2013; Pisano, 2006). Diagnoses of innovation deficits in the pharmaceutical industry and of declining approval rates for drugs and therapies have been prominently cited since the 1970s (Kraft, 2013). The National Institutes of Health $(\mathrm{NIH})$, the US medical research agency, problematizes this issue by stating that "[a] novel drug, device or other invention can take about 14 years and $\$ 2$ billion to develop, with a failure rate exceeding 95 percent" (https://ncats.nih.gov/about). As a consequence, the improvement and acceleration of the translation from research findings into clinical practice has become one of the most important issues in biomedicine "as one of the reasons for this widening gap between input and output is the difficult transition between preclinical ('basic') and clinical stages in the R\&D process" (Wehling, 2008: 1). These unique developments indicate fundamental changes in the way research is organized in the biomedical field. How to improve translation has thus become a prominent question with the spotlight on the transition from preclinical to clinical research and practice.

The issue of translation is controversial, and an expanding literature identifies various problems and possible causes for the lack of translation. Friese (2013) found that providing quality care for laboratory animals is a crucial dimension for the translation of pre-clinical research into clinical practice. Another much discussed example focuses on waste that results from a lack of quality standards in biomedical research studies. Especially influential in that regard was a series of articles published in The Lancet under the headline "Research: increasing value, reducing waste" in January of 2014 (see https:// www.thelancet.com/series/research). A limited number of specific roadblocks for successful translation were emphasized and attributed to lack of methodological skills, research design and analysis (Macleod et al., 2014), publication bias towards the publication of positive research results (Glasziou et al., 2014), decisions about research funding (Chalmers et al., 2014), issues in research management and regulation (Salman et al., 2014), and the role of fully accessible information of biomedical studies (Chan et al., 2014). Recommendations for solving these problems are as varied and numerous as the multitude of issues in the discourse on translational research in general. The stratified nature of the discourse, comprised of heterogeneous sets of definitions of the problem(s), of causes for failing translation, and of necessary measures creates fertile ground for attempts to reduce or shift this multilayered discourse towards unitary concepts that promise to cut through the tangled and puzzling discursive situation. A solitary figure, such as the clinician scientist, promises to be responsible and effective in managing the seemingly unmanageable complexity in translation and thus provides an attractive one-size-fits-all solution (Hendriks et al., 2018).

\section{The clinician scientist}

Who are these clinician scientists and why do they seem so promising at cutting through the layers in the discourse on translational research? In the simplest case, clinician scientists are those rare professionals in the biomedical field holding both an M.D. and a Ph.D. who also work both in clinical care and medical research. Ideally, the time between both areas is evenly split. In general, a more specific and agreed upon job description is not available, and the definition of clinician scientists varies between different national and thus regulatory contexts as well as between different training and funding programs based on specific institutional strategies. However, in order to set a rather consistent definition who clinician scientists are, we follow Zemlo et al. (2000) in defining those individuals as clinician scientists who are working in the clinic, at the bedside, while also performing and understanding research as an essential activ- 
ity in their professional role, at the bench. As such, clinician scientists represent a minority as most scientists producing knowledge relevant to clinical healthcare are not active in clinical practice and most clinicians have no practical link between their work with patients to relevant research projects (Lander et al., 2010).

The practical link between research and clinic provides the source for the clinician scientist' status as the essential conduit to translation. In contrast, 'pure' scientists and clinicians seem to be lacking the necessary interactional expertise to bridge the translational gap. Policymakers and educators have discussed the clinician scientist in this key role for translational research intensively (Garrison and Deschampes, 2014) and a focus on the professional role of clinician scientists has spread from the United States to various countries in Europe-especially Germany (DFG, 2015) and the United Kingdom - as well as to Asia (Woo et al., 2011; Sakushima et al., 2015). As a consequence, educational programs to develop clinician scientists as a professional group and targeted funding strategies were implemented. The overall expectation is that clinician scientists "are able to bring their research from bench to bedside, and they are also uniquely capable of doing the reverseincorporating results of clinical studies into new research and treatment approaches" (Roberts et al., 2012: 267). Thus, we find an increasing demand within science policy to (re-)professionalize the clinician scientist (Vignola-Gagné, 2014; VignolaGagné et al., 2013).

Although the clinician scientist is perceived to be the one capable of successfully translating research findings into clinical practice, the number of clinician scientists is still low (Milewicz et al., 2015). The proportion of physicians engaged in research in the US declined from $3.6 \%$ in 1982 to 1.6\% in 2011 (Morel and Ross, 2014), but different funding and training strategies to promote the clinician scientist aim at counteracting the decline. To put these numbers in context, some historical developments are helpful: Combining research and medical practice has a long tradition, with roots going back to classical antiquity (Schafer, 2009; Rosen, 2011). Until the 1970s, biomedical and clinical research were tightly linked, and research was mainly performed by clinicians.
Medical research was mostly done by so-called physician scientists, who were also responsible for patient care (Butler, 2008; Roberts et al., 2012). The number of clinicians in research decreased from the 1970s onward as a result of structural changes: "[B]iomedical research emerged as a discipline in its own right, with its own training. The bulk of biomedical research is now done by highly specialized PhD scientists [...]" (Butler, 2008: 841). Biomedical research and medical practice got separated, and the clinician scientist became a minority.

Many stakeholders saw the marginalization of the clinician scientist as a challenge and called attention to the problem that they might completely disappear. James B. Wyngaardenwho would later become director of the $\mathrm{NIH}(\mathrm{NIH}$, 2015) — was the first to raise awareness of the tremendous decline in the number of research training fellowships for M.D.s (Wyngaarden, 1979; Garrison and Deschampes, 2014). In 1984, under the headline "The End of the Physician Scientist?", Gordon N. Gill pointed to economic and intellectual changes that made research much less attractive for young physicians, causing further decreasing numbers of clinician scientists. Physicians who engaged in research had increasingly been drawn to laboratory research (Gill, 1984; Garrison and Deschampes, 2014). The situation seemed unchanged in 1999 when Leon Rosenberg wrote that "there is a defect in the structure of the country's medical research edifice, which must be repaired soon [...which is...] the progressive, dangerous decline in the number of physician-scientists" (Rosenberg, 1999: 331). Rosenberg found a growing burden on medical school graduates, an increased length of postdoctoral training, and an instable research career to be the main factors for the decreasing number of physicians participating in biomedical research (Rosenberg, 1999).

The decline of clinician scientists has been analyzed as a problem that had either individual (Löwy, 1987; Lemoine, 2008; Kraft, 2013) or structural (see e.g. Morel and Ross, 2014) causes, but few studies explicitly dealt with how clinician scientists portray their role in the wider biomedical research environment, especially in the context of translational research. In that 
regard, the study from Wilson-Kovacs and Hauskeller (2012) addressing the clinician scientist' self-image in the biomedical research context is relevant. Their case study analyzes how clinician scientists in stem cell research in Germany and the UK portray, explain and justify their role in the clinical research environment. Furthermore, Vignola-Gagné (2014) discusses the paradigm shift to translational research as a cause for selfempowerment of clinician scientists and the work from Brosnan and Michael (2014) addresses the centrality of the clinician scientist figure in visions for translational neuroscience.

More frequent are studies discussing how physicians as a profession are challenged by new concepts of quality and quality standards that are entering the field of biomedical science. Translation is thus but one of the notions that challenge the quality of biomedical research. To give some examples, the study from Fisher (2008) shows how neoliberal mechanisms change the concept and routines of clinical trials and thus the role of the investigators within it. Timmermans and Angell (2001) discuss how the notion of evidence based medicine (EBM) as a quality concept affects the training of medical students. They find that EBM triggers a 'paradigm shift' in training physicians from a rather authoritative education model towards a more sophisticated model, leading to new forms of uncertainty in the daily practice of physicians. More historically oriented, Marks (1997) who studies how the upcoming 'wellcontrolled' study design in the context of clinician trials challenged the credibility of the trained investigator.

We follow up on this line of research by drawing attention to those challenges to the medical professions that refer to translational research. Since clinician scientists take center stage in the discourse on translational research, their selfimage is of strategic importance and can give insights into hurdles and barriers regarding their professional situation and development. The few clinician scientists giving voice to their profession have a high probability of being heard in the wider context of translation and of influencing the construction of problems and solutions in the discourse. We thus ask how clinician scientists portray themselves, what kinds of problems they experience, and how they criticize their biomedical research environment? Answering these questions empirically with an explorative approach by analyzing blogs from clinician scientists allows us to provide insights regarding the ways clinician scientists present a professional self-image and regarding the potential of blogs to provide forms of critique in a digital media ecology.

\section{Decentralized panopticism and critique from blogging selves}

We construct our identities in a media ecology and in societies that have seen significant technological change. Many have argued that the technologies through which we present, represent, and ultimately know ourselves are so pervasive as to amount to societal conditions of visibility (Brighenti, 2007; Turkle, 2005), surveillance (Lyon, 2014), and vigilance (Staples, 2013) that can be called decentralized panopticism (Hörl, 2011; Maasen and Sutter, 2016). Our subjectivity emerges more and more through interactions with technological objects and networked platforms: smartphones, computers, implants, trackers, Facebook, blogging, etc. (Maasen and Sutter, 2016: 176). These put us in heterogeneous actor networks that are characterized by spatio-temporal immediacy (Thompson, 2005). Our communications have audiences beyond our accustomed frames of reference in social space and time (Lyon, 2014). As a consequence, our subjectivity and our identities are the product of collaborative cultures of users in which we participate and which we control through our "blogging selves" (Lovink, 2012). These are not just what we know and do but also what we feel, as they "express personal fear, insecurity, and disillusion [...] and unveil doubts and insecurity about what to feel, what to think, believe, and like" (Lovink, 2008: 17-18).

Our communication within these socio-technical infrastructures may seem trivial or old-fashioned individually, e.g. when the content of our blog posts amounts to nothing more than what we wrote in our diaries long before the internet was invented (Nardi et al., 2004) or when we post family pictures on Instagram that are the same ones we used to put into albums on our book 
shelves. But because the current socio-technical infrastructures give us less visibility as to when and by whom we are seen and read while at the same time maximizing our visibility to others, our blogging selves engage in "self-fashioning" (Greenblatt, 1980). We construct our identities self-reflexively and artfully to account for media ecologies in which we see and are seen through a decentralized panopticon (Maasen and Sutter, 2016). By drawing on the tradition of surveillance studies and emphasizing the world of blogging selves as a decentralized panopticon, the setting in which critique, as a specific form of communication, takes place can be seen as complex and omnipresent. Bloggers are, at least partially, agnostic about who is 'watching' and 'judging.' Critique then has to be articulated in ways that are compatible to various and undefined audiences (Hendriks, 2018) which advance types of professional identity building that are geared towards the global. The analysis on the basis of a decentralized panopticon is thus directed towards the global professional stance of clinician scientists.

In the current digitally networked media ecology, our blogging selves are what we use to participate and create communities (Davies and Horst, 2016a) and through which values are enacted that may form the basis of social movements and collective political action (Davies and Horst, 2016b). Blogging selves thus produce critical moments, and science blogs are places where the blogging selves of scientists provide critique that draws on scientific values. To test empirically how science blogs are a venue for critique that is based on scientific values, we extend surveillance studies by drawing from the neo-pragmatist sociology of critique established by Luc Boltanski and Laurent Thévenot (1999).

The pragmatist tradition within the sociology of critique pays close attention to critical moments as situations in which the conflict between different actors plays out verbally. The conflicting parties draw on their reflexive capacities in order to justify their positions. People have the reflexive ability to distinguish between 'world' and 'reality' and thus to define how the world should ideally be (world) and how it actually is (practice) (Boltanski and Thévenot, 1999). Criticizing is thus a reflexive practice in that blogging selves are fashioned in reaction to those social circumstances that trigger indignation; that again, is constituted by the cognitive differentiation of world and reality. Boltanski and Chiapello (2005) introduced the term indignation to emphasize the meaning of individual critical stances that are emotionally charged with frustration, anger, and rage and raised by people in ordinary day to day situations: "Without this prior emotional-almost sentimental-reaction, no critique can take off" (Boltanski and Chiapello, 2005: 36).

Various aspects of sociality are processed through the bloggers perspective and form a blogging self that represents social reality and its critique through self-fashioning. By describing the world in which the blogger is involved, states of how the world is and how it should be are made visible and form critical moments (Boltanski and Chiapello, 2005: 27). What is rare, however, is that blogging involves a dispute between different parties invoking different orders of worth to justify their respective views. The way Boltanski and Thévenot stipulate that disputes are resolved, either by one order of worth winning over the other or by building compromises (Boltanski and Thévenot, 1999: 374), seem equally rare in the context of blogs.

Blogs are public forms of interaction in which orders of worth are articulated, but the ways they produce critical moments and the means with which they provide justification are different from the pragmatist model within the sociology of critique. Interaction through blogs allows for communication that is not restricted by co-presence in space and time. The setting in which blogging selves articulate themselves hardly resembles the ideal public situation for discourse with face-to-face interaction and, as argued above, is better described as a decentralized panopticon. As a consequence, communication on blogs is not necessarily committed to justification and commonly shared orders of worth and is better described as self-fashioning in a mode that is based on justified indignation. Critique thus takes the form of self-images that are placed within a discourse in which they function as symbols or objects that can be used as one element in justification. We suspect that the blogs of clinician scientists are just such objects, and ones that take 
a central position in the discourse on translational research. Their potential for critique lies not in convincingly argued justifications but in making visible blogging selves that are committed to common scientific as well as clinical values. As a consequence, their daily struggles or frustrations become objects the translational discourse has to contend with.

\section{Method, data, and ethics}

We sampled science blogs within the "web sphere" (Schneider and Foot, 2005: 158) related to translational research and written by clinician scientists. In general, science blogs are numerous and provide plentiful material. Riesch and Mendel (2013) categorize them into four types of science blogging, whereby individual blogs usually contain elements of more than one type. Mainstream media blogs such as "Guardian Science"1 and the BBC blog "Goes the Theory"2 comprise the first type. Second are institutional blogs, e.g. the "Cancer Research UK - Science blog"3. Third are blogs written by practicing scientists addressing their own academic research such as the recently in Nature (Brown and Woolsten 2018) discussed "DoctorAl blog"4. Fourth, and most relevant to our case, are blogs that are only partially perceived as science blogs as they are written by scientists but raise issues that are personal and relate only peripherally to their own academic research but centrally to their working experiences. The "Jack of Kent blog"5 is an example for this category, which gained prominence among science bloggers for the analysis of the Singh libel case. For our study, we selected blogs and blog posts that were written by clinician scientists and that contain 'personal issues,' in line with the fourth type from Riesch and Mendel (2014). The contexts (institutional, mainstream, or private) vary among these blogs.

We started our web search for blogs on the website "Top 100 Science Blogs on the Web"6 and used a 'snowball strategy' mainly through hyperlinks. We collected individual blogs that are hosted by scientific blog networks. In a first step, we collected blogs discussing the concept of translational research in general. In a second step, we reduced the sample to blogs that were written by clinician scientists discussing translational research with respect to their daily working practice, which limited the sample to 32 blogs (see tab 1). The self-description of the blogger had to contain the keywords 'clinician scientist,' 'clinical scientist,' or 'physician scientist.' The sampling strategy further aimed to collect blogs from clinician scientists from diverse biomedical disciplines, diverse job contexts, and job positions as well as institutional settings and national contexts in order to provide insights into a widespread, even global, clinician scientist self-fashioning.

The sample contains research contexts from hematology, oncology, psychiatry, psychology and behavioral science, cancer research, cardiology, and pharmacology. The identified career positions are professors and assistant professors working in university hospitals, research coordinators in governmental institutions, and medical doctors doing their Ph.D. or other research training programs. Not all job positions could be identified. Some of the bloggers also write for newspapers (e.g. "Huffington Post" and "The Guardian") and science magazines.

The most frequent topics within the blogs are the non-compatibility of clinic and research, dealing with working requirements in hospitals (workload and patient care), dealing with research (demands and needs for successful research), education and training (medical degree and clinician scientist program), the economic situation (doctor salary and research funding), and work-life balance.

We selected posts that were published between 2009 and 2016, a time when discourse on translational research in (bio)medicine was already widespread. Blog authors are from the United States of America, Canada, the United Kingdom, India, and China. Most are written by male authors, in line with the underrepresentation of women among clinician scientists (Andrews, 2002; Ley and Rosenberg, 2002; Rosenberg, 1999; Andriole et al., 2008), resulting not from less women entering a career as a clinician scientist but from more women dropping out.

The number of blog posts within any single blog varies as some platforms host more clinician scientist blogs than other platforms, such as "BioMedCentral" or "PsychologyToday." It is up to 
the blogger on which platform they post, but we assume that platforms specialized for a biomedical and psychological audience are more often used from clinician scientists than other blogs that are not specialized for biomedical research, such as "Nature" blog.

Judging from language use and content, the blogs address an anglophone audience with professional biomedical knowledge. In most of the science blogs, a commentary function was available in which anonymous bloggers could comment on the main blog text or previous commentaries. Judging from the comments, the readers seem to hold similar job positions such as clinicians, researchers, medical students, or clinician scientists. Re-comments from clinician scientists were included in our qualitative analysis.

Analytically, we proceeded in two steps. First, we extracted information about structure, issue, length, and wording with linguistic methods (Hewson et al., 2003). Second, a qualitative content analysis (Mayring, 2000) was used to develop appropriate codes inductively and formed the main basis for the interpretation. The coding process was technically supported by the qualitative data analysis software MAXQDA. To ensure reliability of codes, we discussed data and findings frequently in common sessions. Due to the exploratory and inductive approach, part of the analysis was to build a suitable coding scheme through an iterative process. Parts of the material were coded; the emerging codebook was discussed and revised; further parts of the material were coded; the codebook was revised again, until we agreed that a point of saturation was reached (for code book see Table 2 in Appendix 1).

Even though our material consists of publicly available blog posts we, nonetheless, aim to protect the 'internet-identity' of the bloggers as much as possible. Despite a wider discussion on research ethics in online research (Jones, 1994; Bordia, 1996; Buchanan, 2004; Hewson et al.,

Table 1. Coded science blogs

\begin{tabular}{|l|c|c|c|}
\hline Scientific blogs / networks & Blog posts & Words & Comments \\
\hline Scientific American Blog Network & 1 & 2411 & 2 \\
\hline Mind the Brain & 1 & 1547 & 4 \\
\hline BioMedCentral & 4 & 6148 & 9 \\
\hline Kevin MD.com & 1 & 1727 & 5 \\
\hline Science Blogs & 5 & 22035 & 43 \\
\hline Academic Matters & 1 & 1995 & 0 \\
\hline PLOS Blogs Network & 2 & 3607 & 8 \\
\hline Nature.com Blogs & 1 & 1278 & 1 \\
\hline Psychology Today & 4 & 4687 & 1 \\
\hline Psychometrics Forum & 1 & 864 & 0 \\
\hline Asian Scientist & 1 & 799 & 0 \\
\hline Science Mag (AAAS) & 1 & 1794 & 0 \\
\hline Broad Institute MIT, Harvard & 1 & 788 & 0 \\
\hline Research Forum India & 1 & 783 & 2 \\
\hline Give Well Blog & 1 & 3041 & 1 \\
\hline One Earth Future & 1 & 1150 & 0 \\
\hline Queens University & 1 & 608 & 0 \\
\hline Science-Based Medicine & 1 & 5128 & 0 \\
\hline Psychometrics Forum & 1 & 864 & 0 \\
\hline Private Blogs/Other & $\mathbf{3 2}$ & $\mathbf{6 5 9 1 3}$ & 0 \\
\hline Total & 159 & \\
\hline
\end{tabular}


2008), a consensus on which web material should be seen as 'private' is missing (Hookway, 2008). We did not request permission from the bloggers to use their public blog posts as research data but pseudonymized the quoted passages and deliberately selected quotations for publication that contain non-sensitive issues. In line with the argumentation from Hookway (2008), we distinguish between 'public online data' and 'private online data' whereas private data are blogs that are written for'friends only' and this data becomes only accessible by setting up an account. However, in our research we only used public and easily accessible blogs, which may be personal but not private and Walther (2002: 207) suggests that such public accessible data that constitute an Internet archive does not require participant consent.

This study uses an exploratory approach attempting to reveal critical stances from blog posts published by clinician scientists independently from their nationality, gender, or training program in order to give insights about the overall constitution of the professional identity of clinician scientists. Our approach provides a suitable way for the identification of the professional situation of clinician scientists via their public critique that is revealed by their blogging selves, but it also has some limitations. The most critical one is that our study is limited to a small group of clinician scientists who blog actively and problematize their situation as clinician scientists in the daily practice. This study therefore does not provide insights from those clinician scientists who are not active in blogging, and thus their perspective remains invisible to our study.

\section{Empirical findings}

We present and discuss the empirical findings along three lines. In a first step, we outline how clinician scientists establish a critical stance by characterizing and problematizing their own position; this involves specifying what challenges clinician scientists are confronted with. Above all and not surprisingly, much of what clinician scientists problematize can be interpreted as a typical role conflict, in that the blogs voice personal concerns and individual (in)capabilities for action. Second, we reconstruct the patterns of critique indicating a more structural conflict between translation and profession that forms the basis of the role conflict. Third, we integrate the different sources of indignation into a critical agenda for clinician scientists, transforming their self-fashioning into collective political action.

\section{The critical moment as an individual role conflict}

We find two distinct roles for clinician scientists that correspond to the two worlds of research and clinic. The bloggers refer to these two domains by describing their work as having to act in "two worlds" or having to "wear two hats." The perception that clinician scientists combine two different domains is common, in fact it defines who they are. It provides the most fundamental premise for the blog posts in that this combination of the two worlds is framed as problematic and the ensuing account draws essentially from this premise. We call this premise 'the two-world dilemma': Holding the status of a clinician scientist brings the problem of having to combine two distinct worlds. Presenting the two worlds of clinic and research as problematic by those having to "wear two hats" implies a partial incompatibility that may make it difficult to form an identity that draws from both worlds. As a consequence, we start with more exploratory questions: How do clinician scientists describe themselves? What seems to motivate them in their daily working practice? What kind of challenges do they present in their blogs? And what do they criticize in that regard?

The clinician scientist bloggers fashion themselves as primarily motivated in their role as physicians rather than researchers or clinician scientists. Motivation particularly comes from being a medical doctor and thus from improving patients' health. Research, as a daily task, is then perceived as something that disturbs the aim of the clinician, to improve the health of their patients in daily clinical situations. Being a clinician predominates, and other professional tasks are evaluated as subordinate to their daily clinical practice. Reproducing the two worlds of research and clinic as distinct leads to a role conflict, and clinician scientists then prioritize the clinic over the lab. A female clinician scientist from psychiatry made the following statement, exemplifying this process: 
So, soon after starting research training, my unanticipated secondary dilemma became this: committing to conducting serious research appeared to lie in conflict with my desire to be an active clinician. My need to solve important problems in health disparity was, ironically, taking me further from the very patients I wished to serve (Blog V, 2012, par.: 19).

The wish to do research, aimed to "solve important problems in health disparity" (Blog V, 2012, par.: 19), takes the clinician scientist physically away from the patients she actually wanted to help. The idea of combining the two worlds is primarily motivated by helping patients right on site, and the struggles in combining the two worlds set in soon after starting research.

These struggles in combining clinic and research have to be overcome by clinician scientists on a practical level but lead to a specific kind of conflict, as the expectations of both roles would have to, in principle, be met in full and separately within the two distinct worlds. We found that clinician scientists, who represent themselves in science blogs, moreover believe that research and clinic should take an even amount of time, ideally split 50/50. Thus, a reduction of one part, research or clinic, intensifies the conflict. The following statement demonstrates this conflict when research reduces time spent on patient care:

I remember this anecdote so well because in my career as a physician-scientist, the two worlds of science and clinical medicine rarely overlap [...]. Most of my time is spent in my stem cell biology laboratory [...]. Roughly twenty percent of my time is devoted to patient care, treating patients with known cardiovascular disease in clinics, inpatient wards and coronary care units (Blog l, 2014, par.: $10)$.

This 'time gap' represents a fundamental problem dimension for clinician scientists, because it intensifies the conflict between research and clinic. The time for research and clinic affects the different career paths of both roles. Having to fulfill the requirements of both career paths leads to the circumstance that clinician scientists always feel they do not have enough time to do both. Time is very often raised in the blogs as a relevant resource in handling the two worlds. From an individual per- spective, more time for research seems to be the solution for clinician scientists as more time makes it "easier for physicians to be scientists" (Blog II, 2010, par.: 120).
People have been moaning about the lack of physician scientists since at least the 1990s when I was in med school. But no one seems to want to enact the obvious solution: make it easier for physicians to be scientists. Make protected time truly protected, [...] make sure hospitals consider time spent in research as service to the university and don't penalize physicians for not seeing patients during that time, etc. Until that happens of course there will not be many physician scientists. If you make it impossible to do something, people won't do it. End of story (Blog II, 2010, par.: 120).

This statement clarifies that provision is made for research time, but in fact this time is not "protected" enough from clinical obligations. Time becomes especially important with respect to career paths when the option of becoming a full-time researcher or going back to being a fulltime clinician remains possible. If the clinician scientist wants to be successful, more protected time is needed, so that the career requirements for both roles can be fulfilled simultaneously. As a consequence, a career choice away from being a clinician scientist-either towards research or clinic-seems to be a solution. Career choice means therefore choosing between a successful career as a researcher or a physician instead of a clinician scientist.

\footnotetext{
But soon after entering the world of research, and much to my dismay, I discovered what I think is another important reason: the physician-scientist who is able to successfully and simultaneously be both active clinician and clinical researcher is indeed hard to find. Embarking upon the competitive and perilous track toward becoming an independent clinical researcher appears to involve a trade-off-a sizable, if not total reduction in the amount of time spent in providing direct patient care. Something, I imagine, is hard for many physicians to stomach (Blog V, 2012, par.: 14).
}

The clinician scientist career that is fashioned in blogs seems to remain at the edge of two other strong professions either in medicine or science. 
And both professions contain clear tasks and requirements that have to be fulfilled in daily practice. When clinician scientists reflect on those demands, they conclude that the clinician scientist's career path lacks clear descriptions of unique tasks. The resulting feeling is indignation. A blogger articulates one such challenging situation with reference to the work edited by Andrew Schafer (2009) "The Vanishing Physician-Scientist":

[T]he reality, as well as the perception for youngscientists, watching their more established role models attempt to continue in careers as physicianscientists is that most will fail (Blog IX, 2009, par.: 29).

Another clinician scientist remarks that

[c]linician scientists are a rare breed. While the experiences one can obtain on this career path are extremely meaningful and rewarding, the path is also fraught with unpredictability. Most medical students prefer clinical jobs, which not only provide economic assurance but also the flexibility to decide on their extent of involvement in research (Blog XVI, 2013, par: 4).

Although the challenges the bloggers express may seem expected and almost stereotypical, they form the most widely shared description of the basic crisis clinician scientists see themselves in. The two-world dilemma and the time gap provide vocabulary that is understood by all clinician scientist-bloggers. The reason for this vocabulary remaining unspecific we see as an indication that the crisis, on the one hand, is considered larger than can be grasped from an individual perspective and, on the other hand, is not solvable with individual means, such as hybrid forms that allow for simultaneous research and clinical work. The second part of our analysis was thus guided by the following questions: What are indications in the blog posts for the 'larger issues' beyond the individual crisis? What are more specific tasks or forms of work that the bloggers see as 'doing translation'?

\section{The critical moment in context of transla- tion}

The discourse on translation presents clinician scientists as the solution to fundamental translational problems. These include methodological issues such as the lack of individual skills and knowledge with respect to methods. We find that bloggers fashion themselves as the solution to those translational problems in biomedicine:

Traditionally, Clinicians diagnose diseases and treat patients whereas, Scientists do the research work [...]. However there is a gap between clinicians and the scientists. The clinicians, having spent most or rather all of their time with patients do not know about the various research methodologies, for example RT-PCR or Western Blot. On the other hand, the scientists are not familiar with the patient; they just receive the tissue sample that has to be processed. This is precisely why we need some doctors to become Clinician Scientists! (Blog XIX, 2015, par.: 4).

Bloggers in general "agree that [clinician scientists] are in an ideal position to effect translations from bench science into clinical practice" (Blog IX, 2009, par.: 35). However, they also critically note that translation needs more than just a few individuals who speak the two languages of research and clinic. Translation particularly depends on individuals who are able to let those languages communicate:

The mark of a good "translator" is not merely the ability to understand and speak both languagesresearch and medical-but to let the two languages communicate (Blog XIX, 2016, par.: 15).

Doing translation on a professional level thus means more than just practicing research and clinic side by side. In order to link lab and clinic it needs "good translators," i.e. individuals who are able to transform laboratory work and clinical practice into translational research. With that competence,

[c]linician-scientists can be [...] knowledge brokers or bridge builders. In our highly specialized medical and research modern environment, they possess an interesting and much needed profile allowing them to make connections between people and expertise (Blog XVII, 2015, par.: 63). 
The clinician scientist role is pictured as to be able to withstand the ongoing trend of specialization that pushes research and clinic away from each other. This picture is in line with the discourse on translational research that demands successful communication between biomedical research and clinical practice in order to provide translation. However, bloggers criticize that biomedicine, despite the fact that it claims translation, does not represent translational research. The two domains of research and clinic are reproduced permanently in daily business. Conferences, for instance, as a potential place for interdisciplinary exchange are highly specialized towards either basic research or clinical practice. These circumstances, when reflecting the gap between reality and world, lead to feelings of indignation as these daily tasks, such as giving talks at conferences, are clearly lacking the aim of translation:

Here, instead, I wish to articulate the feeling that these talks evoke in me, a feeling I suspect is shared among countless clinician researchers and even some, yes, if you'll believe it, physician scientists, who might admit this only in private. That feeling is: "No. Please stop. Dear God. Please. Stop. I beg you." [...] But, no matter whether you think of molecular medicine as salvation or self-promotion, can we at least agree that the talks are boring? They bore the clinician-physician [as part of the clinician scientist] in all of us who is concerned with how people live in sickness and health and what medicine does, can do, and should do to help them (Blog VII, 2012, par.: 7 - 11).

These critical stances from the bloggers reveal that research and clinic coexist rather than overlap or even intertwine in daily practice. Although there is this overall accepted notion that lab and clinic should be linked in order to perform research quality in (bio)medicine, the actual daily routines seem to hinder a stable linkage. The following statement reflects the impossibility of furthering a clinician scientist career due to everyday constraints.

Clinician-scientists no longer drive biomedical research. It is not possible to be truly proficient in both modern clinical care and experimental basic science. In addition, and because they rarely elucidate the latest biological mechanism, their research output will not always be considered as they would have wished by some basic scientists and top tier scientific journals. The constraints of the daily routine of medical practice, including the increasing financial pressure on the health system, lack of time and even the lack of training are major obstacles to the development of broader research activity within academic teaching hospitals (Blog XV, 2015, par.: 56).

Overall, bloggers seem willing to transform daily practices towards translation but blame a clinical environment that seems rigid and not (yet) open for translation. Such a supportive environment is needed for individuals to persistently perform the role of a clinician scientist. When problematizing environmental conditions, policy regulations are foregrounded. One blogger stated this incompatibility between translational aspirations and established routines succinctly to the point:

I am skeptical of some of the arguments people have made for the importance of translational science. These arguments often do not distinguish between different possible definitions of "translational science," and often do not make a strong case that nonprofit funding (as opposed to industry funding) is what's needed. In addition, it seems quite possible to me that the goals of promoting "translational science" might be better served by policy change (on regulatory and intellectual property law, for example) than by [an individual's] scientific research. With that said, I think the idea of translational science is worth keeping in mind, and that certain kinds of research in this category could be under-invested in because they do not fit cleanly into an academic or for-profit framework (Blog XIV, 2015, par.: 52).

Translational research sets new quality standards in order to perform biomedical research. In this context, clinician scientists must be good translators to achieve successful communication between lab and clinic. By doing translationcombining research and clinic successfully-clinician scientists meet the existing expectation of becoming a knowledge broker. However, in day-to-day practice clinician scientists do not find themselves in a research environment that rewards translational practices, leading some clinician scientists to the opinion that translational research should be regulated more on a policy 
level rather than by individual clinician scientists, who are in need of stable support mechanisms.

\section{Discussion}

We started by noting that clinician scientists participate in the discourse on translational research by being seen as pivotal for translational success. As a consequence, the self-fashioning of clinician scientists is more than identity work of an emerging profession; it holds the potential for critique that carries weight. We have seen that the blogging selves of clinician scientists mark a critical moment through the two-world dilemma and the time gap. These critical moments draw from a more complex notion of translation that is rooted in daily working practice. From these more complex notions, it becomes more tangible how the role of science blogs as a platform that allows for transforming individual blogs into a general (embodied) critique. We summarize our findings regarding this landscape of critique by formulating a critical agenda for clinician scientists. This critical agenda is based on indignation, a critical capacity individuals are equipped with, expressed by bloggers individually and by the situation of decentralized panopticism. We find different sources of indignation that relate to the pivotal role of clinician scientists in the discourse on translational research. These reflect the critical stances towards experienced uncertainties in daily working practice:

a) To be a pivotal figure in translational research triggers feelings of contradiction as it demands a combination of research and clinic in the daily working practice, i.e. translation should be based on the combination of lab and clinic (world), yet combining the two different roles can hardly be fulfilled in everyday work. The worlds of research (publishing, applying for grants, lab supervising, and research projects) and clinical practice (patient care, improving patient health, and clinical duties) are too specialized to combine them successfully in everyday work (reality).

b) The circumstance that clinician scientists have to act in a highly specialized professional environment that, in particular, rewards either biomedical research or clinical practice (reality) triggers feelings of unpredictability regarding individual career paths. Biomedical research should reward translational practices (world), but rather research and clinic coexist and do not intertwine in daily practices. These circumstances cause a permanent time gap for clinician scientists, who face the challenge of meeting the requirements of both roles simultaneously in their daily working practice.

c) Translational research triggers feelings of skepticism, because while it seeks to consolidate research and clinic (world), it actually reproduces both worlds continuously as separate. Translational research lacks regulatory and/ or organizational mechanisms to combine research and clinic, which neither offers precise information for the individuals involved on how to practice translation successfully nor rewards translation (reality).

\section{Conclusion}

Translational research promises to solve many of the key challenges (bio)medicine faces today, sometimes polemically referred to as 'overcoming the valley of death' or 'reducing research waste'. In our analysis these challenges are the result of specialization and ensuing professional quality concerns in the biomedical field. This is what the discourse on translational research refers to and why it assigns clinician scientists a pivotal role in overcoming these challenges. Even though many observers have predicted or analyzed the discourse on translational research as favorable for the clinician scientists to regain professional strength, the critical view of clinician scientists themselves has received little attention. We analyzed science blogs by clinician scientists to describe their blogging selves within the discourse on translational research by paying special attention to their potential for critique.

Our approach is rooted in research on science communication (see e.g. Bonetta, 2007; Bucchi, 1998; Shanahan, 2011) in the field of biomedicine and extends this STS perspective through the neo-pragmatist sociology of critique by Boltanski and Thévenot. This allows, on the one hand, to use online data to understand the social construction of professional identities in biomedicine. On the other hand, it shows these identities to be 
constructed from the critical capacities of individual professionals against the backdrop of a larger discourse (i.e. translational research).

We found that clinician scientists fashion themselves prima facie in a dilemma between the two worlds of research and clinical practice, which does not afford them enough time to fulfill either role-as researcher or as clinician-sufficiently. By interpreting this conflict in the context of translational research, we find a more deep-rooted professional challenge facing the clinician scientist profession: With its vague definition, translational research does not offer enough guidance on how to practice translation successfully. Leaving clinician scientists with the demand of combining research and clinic, despite the mismatch between translational ideals and professional guidance.

Despite all the promises and potential of translational research, the view that emerges from blogs of clinician scientists is critical. Their selffashioning offers forms of critique that rest more on structural rather than individual challenges. The demand of being a clinician scientist is an overall source of uncertainty regarding individual career paths. It provokes a high individual risk of not fulfilling the expectations for either of the two separate career paths. However, clinician scientists accept their role as being responsible individually for making translational research work. Even though much of the discourse on translational research envisions solutions that are organizational, political, or infrastructural, clinician scientists seem trapped in a form of uncertainty that is a double bind: Accept your pivotal role and bear the price of incompatible expectations or redefine the translational in your work and risk losing your pivotal role. Indignation then is the consequential mode of critique that forms a critical agenda when conceptualizing the world of blogs as a decentralized panopticon, a public stage allowing clinician scientists to utter their critique to a wide audience. Showing feelings of contradiction, unpredictability, and skepticism forms a critique of translational research as a source of indignation. These feelings reflect major uncertainties which the individual bloggers experience within their clinician scientist career that result from mismatches between the imagination of translation, as it ideally should be, and the actual practice of trans- lation buried in an existing biomedical research environment. Without losing their pivotal role, this critique is limited to performing blogging selves that are overstrained by uncertainty. However, it remains effective in working to shape this pivotal role in the discourse on translational research.

Two, more general, questions emerge from our study that may extend research in science communication and in the sociology of critique, respectively. For science communication: How is individual critique rendered effective in digital media ecology? In our study, individual capacities for critique align with the discourse on translational research. As a result the professional critique from individual scientists is performed as individual dissatisfaction with work arrangements. What would it take in the context of digital media for critique either to be shared and performed as collective interests or to emerge from conflict between different parties? The latter would be expected from the sociology of critique and our case thus extends this perspective with questions regarding how public critique is verbally not only inscribed in protest and dispute but also on alternative and new communication platforms such as online blogs. In our case we interpret blogging selves as critical voices in the discourse on translation even though there is no discernible dispute between different parties. The resulting question should be of concern to the sociology of critique in the future: What are minimal criteria for online communication to still be considered as critique?

To conclude, it remains an open question, if such critical voices are heard given the decentralized shape of translational medicine-and if they are heard-by whom and to what effect? In other words: How does the voiced critique in science blogs change those social conditions the actors criticize? Further empirical research could help to enlighten the role of critique in science blogs as a condition for social change in biomedicine and more broadly.

\section{Acknowledgements}

We would like to thank Barbara Sutter, Jürgen Gerhards and Lisa Bankowski for their constructive discussions. We also want to thank the anonymous reviewers for their helpful advice on earlier versions of this article. 


\section{References}

Andrews NC (2002) The other physician-scientist problem: Where have all the young girls gone? Nature Medicine 8(5): 439-441.

Andriole DA, Whelan AJ and Jeffe DB (2008) Characteristics and Career Intentions of the Emerging MD/PhD Workforce. JAMA 300(10): 1165-1173.

Blümel C, Gauch S, Hendriks B, Krüger A and Reinhart M (2015) In Search of Translational Research: Report on the Development and Current Understanding of a New Terminology in Medical Research and Practice. iFQBIH-Report. Berlin: Institute for Research Information and Quality Assurance; Humboldt-University Berlin. Available at: https://www.bihealth.org/uploads/pics/iFQ-BIH-Report_2015_web.pdf (accessed 7.3.2019).

Bodell S, Angela Hook, Merrolee Penman, et al. (2009) Creating a Learning Community in Today's World: How Blogging Can Facilitate Continuing Professional Development and International Learning. British Journal of Occupational Therapy 72(6): 279-281.

Boltanski L and Chiapello E (2005) The New Spirit of Capitalism. International Journal of Politics, Culture, and Society 18(3-4): 161-188.

Boltanski L and Thévenot L (1999) Sociology of critical capacity. European Journal of Social Theory (2): 359-377.

Boltanski L and Thévenot L (2006) On Justification: Economies of Worth. Princeton: Princeton University Press.

Bonetta L (2007) Scientists Enter the Blogosphere. Cell 129(3): 443-445.

Bordia P (1996) Studying verbal interaction on the Internet: The case of rumor transmission research. Behavior Research Methods, Instruments, \& Computers 28(2): 149-151.

Brighenti A (2007) Visibility: A Category for the Social Sciences. Current Sociology 55(3): 323-342.

Brosnan C and Michael M (2014) Enacting the 'neuro' in practice: Translational research, adhesion and the promise of porosity. Social Studies of Science 44(5): 680-700.

Brown E and Woolston C (2018) Why science blogging still matters. Nature 554: 135. DOI: 10.1038/d41586018-01414-6.

Bucchi M (1998) Science and the Media : Alternative Routes in Scientific Communication. London, New York: Routledge.

Buchanan EA (2004) Readings in Virtual Research Ethics: Issues and Controversies. Hershey, PA: Information Science Publishing.

Butler D (2008) Translational research: Crossing the valley of death. Nature News 453(7197): 840-842.

Center Watch (2016) 2016 FDA Approved Drugs. Boston, MA: Center Watch.

Chalmers I, Bracken MB, Djulbegovic B et al. (2014) How to increase value and reduce waste when research priorities are set. The Lancet 383(9912): 156-165.

Chan A-W, Song F, Vickers A et al. (2014) Increasing value and reducing waste: Addressing inaccessible research. The Lancet 383(9913): 257-266.

Contopoulos-loannidis DG, Ntzani EE and loannidis JPA (2003) Translation of highly promising basic science research into clinical applications. The American Journal of Medicine 114(6): 477-484.

Davies S and Horst M (2016a) Identities: How Scientists represent Collectives, construct Identities, and make sense of Science. In: Davies S and Horst M (eds) Science Communication - Culture, Identity and Citizenship. Palgrave Macmillan UK, pp. 53-77.

Davies S and Horst M (2016b) Scientific Citizenship: The Role of Science Communication in Democracy. In: Davies $\mathrm{S}$ and Horst M (eds) Science Communication - Culture, Identity and Citizenship. Palgrave Macmillan UK, pp. 187-211. 
DFG (2015) Etablierung eines integrierten Forschungs- und Weiterbildungs- Programms für "Clinician Scientists" parallel zur Facharztweiterbildung Empfehlungen der Ständigen Senatskommission für Grundsatzfragen in der Klinischen Forschung der Deutschen Forschungsgemeinschaft. April. Bonn: Deutsche Forschungsgemeinschaft. Available at: http://www.dfg.de/download/pdf/dfg_im_profil/reden_stellungnahmen/2015/ empfehlungen_clinician_scientists_0415.pdf (accessed 7.3.2019).

Ezzamel S (2013) Blogging in Occupational Therapy: Knowledge Sharing, Professional Development, and Ethical Dilemmas. British Journal of Occupational Therapy 76(11): 515-517..

Farrell H and Drezner DW (2008) The power and politics of blogs. Public Choice 134(1-2): 15.

Farrell H and Sides J (2010) Building a Political Science Public Sphere with Blogs. The Forum 8(3).

Fisher JA (2009) Medical Research for Hire: The Political Economy of Pharmaceutical Clinical Trials. New Brunswick, NJ: Rutgers University Press.

Friese C (2013) Realizing Potential in Translational Medicine: The Uncanny Emergence of Care as Science. Current Anthropology 54(S7): 129-138.

Garrison HH and Deschampes AM (2014) NIH research funding and early career physician scientists: Continuing challenges in the 21st century. The FASEB Journal 28: 1049-1058.

Gill GN (1984) The end of the physician-scientist? American Scholar 53: 353-69.

Glasziou P, Altman DG, Bossuyt P et al. (2014) Reducing waste from incomplete or unusable reports of biomedical research. The Lancet 383(9913): 267-276.

Greenblatt S (1980) Renaissance Self-Fashioning. Chicago: The University of Chicago Press.

Hendriks B (2018) Virtuelle Identitäten. In: Lettkemann E, Wilke R and Knoblauch H (eds) Knowledge in Action: Neue Formen der Kommunikation in der Wissensgesellschaft. Wissen, Kommunikation und Gesellschaft. Springer VS, Wiesbaden, pp. 191-211.

Hendriks B, Simons A and Reinhart M (2019) What are Clinician Scientists Expected to do? The Undefined Space for Professionalizable Work in Translational Biomedicine. Minerva. DOI: 10.1007/s11024-01909367-4.

Hewson C, Yule P, Laurent D et al. (2003) Internet Research Methods: A Practical Guide for the Social and Behavioural Sciences. New technologies for social research. London: Sage Publications.

Hookway N (2008) 'Entering the blogosphere': Some strategies for using blogs in social research. Qualitative Research 8(1): 91-113.

Hörl E (2011) Die technologische Bedingung: Beiträge zur Beschreibung der technischen Welt. Berlin: Suhrkamp Verlag.

Jones A (1994) The Ethics of Research in Cyberspace. Internet Research 4(3): 30-35.

Kouper I (2010) Science blogs and public engagement with science: Practices, challenges, and opportunities. Journal of Science Communication 9(1): 1-10.

Kraft A (2013) New Light Through an Old Window?: The 'Translational Turn' in Biomedical Research: A Historical Perspective. In: Mittra J and Milne C-P (eds) Translational Medicine.The Future of Therapy? Singapore: Pan Stanford Publishing, pp. 19-55.

Krüger AK, Hendriks B and Gauch S (2018) The multiple meanings of translational research. Negotiating medical science. Doi: 10.31235/osf.io/w6xjn.

Lander B, Hanley GE and Atkinson-Grosjean J (2010) Clinician-scientists in Canada: barriers to career entry and progress. PloS One 5(10).

Lemoine NR (2008) The clinician-scientist: a rare breed under threat in a hostile environment. Disease Models and Mechanisms 1(1): 12-14. 
Ley TJ and Rosenberg LE (2002) Removing Career Obstacles for Young Physician-Scientists — Loan-Repayment Programs. New England Journal of Medicine 346(5): 368-372.

Lovink G (2008) Zero Comments: Blogging and Critical Internet Culture. New York: Routledge.

Lovink G (2012) Das halbwegs Soziale: Eine Kritik der Vernetzungskultur. 1., Aufl. Bielefeld: Transcript.

Löwy I (1987) The impact of medical practice on biomedical research: The case of human leucocyte antigens studies. Minerva 25: 171-200.

Lyon D (2014) Surveillance, Snowden, and Big Data: Capacities, consequences, critique. Big Data \& Society 1(2). Doi: 2053951714541861.

Maasen S and Sutter B (2016) Dezentraler Panoptismus. Geschichte und Gesellschaft 42(1): 175-194.

Macleod MR, Michie S, Roberts I et al. (2014) Biomedical research: increasing value, reducing waste. The Lancet 383(9912): 101-104.

Marks HM (2000) The Progress of Experiment: Science and Therapeutic Reform in the United States, 1900-1990. 1 edition. Cambridge: Cambridge University Press.

Mayring P (2000) Qualitative Content Analysis. Forum Qualitative Sozialforschung / Forum: Qualitative Social Research 1(2). Doi: 10.17169/fqs-1.2.1089.

Milewicz DM, Lorenz RG, Dermody TS and Brass LF (2015) Rescuing the physician-scientist workforce: the time for action is now. Journal of Clinical Investigation 125(10): 3742-3747.

Morel PA and Ross G (2014) The physician scientist: balancing clinical and research duties. Nature Immunology 15(12): 1092-1094.

Nardi BA, Schiano DJ and Gumbrecht M (2004) Blogging As Social Activity, or, Would You Let 900 Million People Read Your Diary? In: Proceedings of the 2004 ACM Conference on Computer Supported Cooperative Work, New York, NY, USA, 2004, pp. 222-231. CSCW '04. ACM.

NIH (2015) Physician-Scientist Workforce (PSW) Report 2014. Chapter 2: The Physician-Scientist Workforce: Past, Present, \& Future. Research Portfolio Online Reporting Tools (RePORT). Bethesda: NIH. Available at: https:// report.nih.gov/workforce/psw/historical_concerns.aspx (accessed 2 December 2015).

Pisano GP (2006) Can Science be a Business?: Lessons from Biotech. Havard Business Review (10): 114-125.

Riesch H and Mendel J (2014) Science Blogging: Networks, Boundaries and Limitations. Science as Culture 23(1): 51-72.

Roberts S, Fischhoff MA, Sakowski SA, et al. (2012) Perspective: Transforming science into medicine: How clinician-scientists can build bridges across research's 'valley of death'. Academic Medicine: Journal of the Association of American Medical Colleges 87(3): 266-270.

Rosen MR (2011) The Role of the Physician-Scientist in Our Evolving Society. Rambam Maimonides Medical Journal 2(4). Doi: 10.5041/RMMJ.10063.

Rosenberg LE (1999) Physician-Scientists-Endangered and Essential. Science 283(5400): 331-332.

Sakushima K, Mishina H, Fukuhara S et al. (2015) Mentoring the next generation of physician-scientists in Japan: a cross-sectional survey of mentees in six academic medical centers. BMC medical education 15: 54.

Salman RA-S, Beller E, Kagan J et al. (2014) Increasing value and reducing waste in biomedical research regulation and management. The Lancet 383(9912): 176-185.

Schafer Al (2009) The history of physican as scientist. In: The Vanishing Physician-Scientist? Ithaca, NY: Cornell University Press, pp. 17-38.

Schneider SM and Foot KA (2005) Web Sphere Analysis: An Approach to Studying Online Action. In: Hine C (ed) Virtual Methods: Issues in Social Science Research on the Internet. Oxford: Berg, pp. 157-170. 
Shanahan M-C (2011) Science blogs as boundary layers: Creating and understanding new writer and reader interactions through science blogging. Journalism 12(7): 903-919.

Staples WG (2013) Everyday Surveillance: Vigilance and Visibility in Postmodern Life. Lanham, Md: Rowman and Littlefield.

Thompson JB (2005) The New Visibility. Theory, Culture \& Society 22(6): 31-51.

Timmermans S and Angell A (2001) Evidence-Based Medicine, Clinical Uncertainty, and Learning to Doctor. Journal of Health and Social Behavior 42(4): 342-359.

Turkle S (2005) The Second Self. Computers and the Human Spirit. Cambridge, MA; London: MIT Press.

Vignola-Gagné E (2014) Argumentative practices in science, technology and innovation policy: The case of clinician-scientists and translational research. Science and Public Policy 41(1): 94-106.

Vignola-Gagné E, Rantanen E, Lehner D et al. (2013) Translational research policies: disruptions and continuities in biomedical innovation systems in Austria, Finland and Germany. Journal of Community Genetics 4(2): 189-201.

Walther JB (2002) Research ethics in Internet-enabled research: Human subjects issues and methodological myopia. Ethics and Information Technology 4(3): 205-216.

Wehling M (2008) Translational medicine: science or wishful thinking? Journal of Translational Medicine 6(31).

Westfall JM, Mold J and Fagnan L (2007) Practice-Based Research: "Blue Highways" on the NIH Roadmap. Journal of American Medical Association 297(4): 403-406.

Wilson-Kovacs DM and Hauskeller C (2012) The clinician-scientist: professional dynamics in clinical stem cell research. Sociology of Health \& IIlness 34(4): 497-512. DOI: 10.1111/j.1467-9566.2011.01389.x.

Woo KT, Wong KS, Lee EJC and Chan CM (2011) How can we improve clinical research in clinical practice with better research outcome? Annals of the Academy of Medicine, Singapore 40(11): 499-506.

Wyngaarden JB (1979) The Clinical Investigator as an Endangered Species. The New England Journal of Medicine 301: 1254-1259.

Zemlo TR, Garrison HH, Partridge NC and Ley TJ (2000) The Physician-Scientist: Career Issues and Challenges at the Year 2000. FASEB journal: official publication of the Federation of American Societies for Experimental Biology 14: 221-230.

\section{Notes}

1. https://www.theguardian.com/science/series/science-blog-network. Last access date: March 11, 2019.

2. http://www.bbc.co.uk/blogs/tv/2012/03/bang-goes-the-theory.shtml. Last access date: April 3, 2016. This page has been archived and is no longer updated.

3. http://scienceblog.cancerresearchuk.org. Last access date: March, 11, 2019.

4. https://aemcdonald.wordpress.com. Last access date: March 12, 2019.

5. http://jackofkent.com. Last access date: April 3, 2017. Blogger moved his contents to twitter: https:// twitter.com/jackofkent. Last access date: March 4, 2019.

6. https://blog.feedspot.com/science_blogs/. Last access date: March, 11, 2019. 


\section{Appendix 1.}

Table 2. Code book

\begin{tabular}{|c|c|c|c|}
\hline Main categories & Information in Codes & $\begin{array}{l}\text { Themes and } \\
\text { questions of codes }\end{array}$ & $\begin{array}{l}\text { Number of codings (incl. } \\
\text { cross coding elements) }\end{array}$ \\
\hline \multirow{4}{*}{$\begin{array}{l}\text { Background } \\
\text { Information }\end{array}$} & Name and origin of blog & \multirow{2}{*}{$\begin{array}{l}\text { How is the blog named? } \\
\text { Where is the blog } \\
\text { published? When was } \\
\text { the blog released? }\end{array}$} & \multirow[t]{4}{*}{113} \\
\hline & Date of release & & \\
\hline & $\begin{array}{l}\text { Job position and } \\
\text { research field }\end{array}$ & $\begin{array}{l}\text { Which kind of job position } \\
\text { does the blogger held? } \\
\text { What is the research } \\
\text { field of the blogger? }\end{array}$ & \\
\hline & $\begin{array}{l}\text { Sex (of bloggers and } \\
\text { commentators) }\end{array}$ & $\begin{array}{l}\text { Gender of blogger } \\
\text { and commentators }\end{array}$ & \\
\hline Reference groups & $\begin{array}{l}\text { Relevant (named) } \\
\text { reference groups }\end{array}$ & $\begin{array}{l}\text { Interpersonal } \\
\text { communication, } \\
\text { relationships and contacts } \\
\text { (e.g. with academic } \\
\text { staff, clinical staff, } \\
\text { family members, etc.) }\end{array}$ & 74 \\
\hline \multirow[t]{4}{*}{$\begin{array}{l}\text { Public Identity } \\
\text { - Defining } \\
\text { the clinician } \\
\text { scientist role }\end{array}$} & $\begin{array}{l}\text { Translational } \\
\text { research practice }\end{array}$ & $\begin{array}{l}\text { Working and research } \\
\text { contexts, research } \\
\text { conditions, aspects of } \\
\text { knowledge transfer, } \\
\text { collaborations }\end{array}$ & \multirow[t]{4}{*}{185} \\
\hline & $\begin{array}{l}\text { Expectations regarding } \\
\text { clinician scientist role }\end{array}$ & $\begin{array}{l}\text { Formal working criteria, } \\
\text { working time, policy } \\
\text { regulations, overall } \\
\text { working conditions, } \\
\text { education and } \\
\text { educational training, } \\
\text { work-life-balance }\end{array}$ & \\
\hline & Worth and values of TR & $\begin{array}{l}\text { Why should translational } \\
\text { research be done? } \\
\text { What are general aims } \\
\text { of research and clinical } \\
\text { practice, and their } \\
\text { contribution for TR? }\end{array}$ & \\
\hline & Motivation & $\begin{array}{l}\text { What motivates } \\
\text { the blogger to be a } \\
\text { clinician scientist? }\end{array}$ & \\
\hline
\end{tabular}




\begin{tabular}{|c|c|c|c|}
\hline Main categories & Information in Codes & $\begin{array}{l}\text { Themes and } \\
\text { questions of codes }\end{array}$ & $\begin{array}{l}\text { Number of codings (incl. } \\
\text { cross coding elements) }\end{array}$ \\
\hline \multirow[t]{4}{*}{$\begin{array}{l}\text { Conflicts } \\
\text { between } \\
\text { research and } \\
\text { medicine }\end{array}$} & $\begin{array}{l}\text { Reproduction of } \\
\text { two worlds (research } \\
\text { and clinic) }\end{array}$ & $\begin{array}{l}\text { In which way are the } \\
\text { distinct worlds of clinical } \\
\text { practice and research } \\
\text { reproduced? How are } \\
\text { both worlds thematized } \\
\text { and criticized? How often } \\
\text { are both worlds named } \\
\text { and in which context? }\end{array}$ & \multirow[t]{4}{*}{316} \\
\hline & $\begin{array}{l}\text { Self-descriptions } \\
\text { and self-definition }\end{array}$ & $\begin{array}{l}\text { How do the blogger } \\
\text { define themselves? } \\
\text { What are priorities in } \\
\text { the identity process of } \\
\text { clinician scientists? }\end{array}$ & \\
\hline & Problem dimension & $\begin{array}{l}\text { What are the main } \\
\text { problems by handling the } \\
\text { two roles? What are key } \\
\text { conflicts regarding each } \\
\text { role (research and clinic)? }\end{array}$ & \\
\hline & Time dimension & $\begin{array}{l}\text { How does the time } \\
\text { dimension strengthen } \\
\text { the role conflict? What } \\
\text { kinds of problems are } \\
\text { produced by limited time? }\end{array}$ & \\
\hline Total & & & 688 \\
\hline
\end{tabular}

